\title{
ANÁLISE MICROBIOLÓGICA DE SALADAS E ÁGUA SERVIDAS EM UM RESTAURANTE UNIVERSITÁRIO DO TRIÂNGULO MINEIRO, MINAS GERAIS, BRASIL
}

\author{
Emanuelle do Nascimento Santos Lima ${ }^{1}$ Renata Aparecida Mendes ${ }^{1}$ Alexandre \\ Bicalho do Amaral ${ }^{2}$ Kênia de Fátima Carrijo ${ }^{2}$ \\ ${ }^{1}$ Faculdade de Medicina, Universidade Federal de Uberlândia - Uberlândia-MG- \\ Brasil (renata@famed.ufu.br). \\ ${ }^{2}$ Faculdade de Medicina Veterinária, Universidade Federal de Uberlândia- \\ Uberlândia-MG-Brasil.
}

Recebido em: 08/09/2015 - Aprovado em: 14/11/2015 - Publicado em: 01/12/2015 DOI: http://dx.doi.org/10.18677/Enciclopedia_Biosfera_2015_033

\begin{abstract}
A ingestão de alimentos contaminados com micro-organismos patogênicos pode causar doenças, sendo de extrema importância a investigação da qualidade microbiológica das refeições e da água oferecidas nos estabelecimentos produtores. O Objetivo do presente trabalho foi avaliar a qualidade microbiológica das saladas, seus ingredientes e da água servidas em um Restaurante Universitário do Triângulo Mineiro. Foram avaliadas 10 amostras de salada, 10 amostras de ingredientes e cinco amostras de água quanto ao número mais provável de coliformes totais e termotolerantes, segundo metodologia proposta pela American Public Health Association (APHA). Das amostras de salada e ingredientes analisados, $40 \%$ e $30 \%$, respectivamente, apresentaram coliformes termotolerantes em níveis superiores aos permitidos pela legislação sanitária vigente, $100 \mathrm{NMP} / \mathrm{g}$. A análise das amostras de água revelou que todas estavam adequadas para o consumo humano. Apesar dos resultados satisfatórios para as amostras de água, os resultados constatados para saladas e seus ingredientes indicam falhas na aplicação das boas práticas, que necessitam ser corrigidas por meio de maior controle sobre os fornecedores e etapas de preparação e por treinamentos para os manipuladores.
\end{abstract}

RESUMO

PALAVRAS- CHAVE: Coliformes, higiene dos alimentos, qualidade da água.

\section{MICROBIOLOGICAL ANALYSIS OF WATER AND SALADS SERVED IN A UNIVERSITY RESTAURANT OF TRIANGULO MINEIRO REGION, MINAS GERAIS STATE, BRAZIL}

\footnotetext{
ABSTRACT

The ingestion of food contaminated with pathogenic microorganisms can cause disease. It is extremely important to investigate the microbiological quality of the meals and water offered in food services. The objective of this study was to evaluate the microbiological quality of water and salads served in a university restaurant of Triangulo Mineiro region, Brazil. We analyzed 10 samples of salad, 10 samples of ingredients and 5 samples of water for total and fecal coliforms by the most probable 
number technique, according to the methodology proposed by the American Public Health Association (APHA). 40\% and 30\%, respectively, of the samples analyzed of salad and ingredients showed fecal coliform levels above those allowed by the current health legislation, $100 \mathrm{MPN} / \mathrm{g}$. The analysis of water samples revealed that they were all suitable for human consumption. Despite the satisfactory results for water samples, the results observed for salads and ingredients indicate flaws in the implementation of good practices that need to be corrected through greater control over suppliers and process and training for food handlers.

KEYWORDS: Food safety, water quality, coliforms.

\section{INTRODUÇÃO}

O consumo de alimentos fora de casa tem aumentado significativamente no Brasil (BEZERRA et al., 2013). Segundo AKUTSU et al. (2005), a cada cinco refeições realizadas pelos brasileiros, uma é feita fora do domicílio. Esse processo deve-se, principalmente, pela mudança do estilo de vida e comportamento alimentar da população, em que cada vez mais pessoas se alimentam em serviços de alimentação comerciais e coletivos, como aqueles presentes em creches, escolas e centros universitários (AKUTSU et al., 2005).

De acordo com o artigo $2^{\circ}$ da Lei $n^{\circ} 11.346$ (BRASIL, 2006) uma alimentação adequada é direito fundamental do ser humano. O Codex Alimentarius dispõe que o alimento seguro é aquele que não acarreta prejuízo à saúde de quem os consome (CODEX ALIMENTARIUS, 2002).

Sabe-se que alimentos preparados em larga escala estão cada vez mais envolvidos em casos de surtos alimentares, frequentemente associados à contaminação microbiana (MENDES et al., 2011; NUNES, 2013). De acordo com dados do Ministério da Saúde (BRASIL, 2014), registros epidemiológicos de 20002014 demostraram a ocorrência de 9.719 casos de surtos por doenças transmitidas por alimentos, sendo destes 563 pela ingestão de água e 118 pelo consumo de hortaliças. Os dados revelam ainda que os restaurantes são fonte de parte desses casos (1492), e constituem o segundo local onde ocorrem mais surtos alimentares, antecedendo apenas as residências. Ainda que o número de surtos registrados no Brasil seja subestimado, a relevância é reconhecida (MENDES et al., 2011).

As doenças transmitidas por alimentos ocorrem pela ingestão de água ou alimentos contaminados com agentes químicos ou biológicos, sendo a contaminação de alimentos por agentes biológicos através de micro-organismos a causa mais frequente (AMSON et al., 2006; SANTOS et al., 2015). A contaminação de alimentos com águas também deve ser considerada, pois, se nestas estiverem presentes micro-organismos patogênicos, poderão causar doenças, comprometendo a saúde dos consumidores (JERBA \& PILEGGI, 2000).

Em unidades de alimentação e nutrição, a contaminação dos alimentos pode ocorrer em todas as etapas do processamento, desde o armazenamento até a distribuição (KOCHANSKI et al., 2010). O problema assume maior relevância quando os produtos consumidos são expostos a milhares de pessoas, diariamente, como é o caso dos restaurantes universitários. Nesses locais, as grandes quantidades de alimentos produzidos passam, frequentemente, por lentas operações de resfriamento ou por períodos de espera pós-cozimento, suficientemente longos para permitir que as populações microbianas alcancem níveis perigosos (MENDES et al., 2004). 
O consumo de vegetais é de extrema importância por serem alimentos ricos em vitaminas, minerais e fibras, além de possuírem baixo valor energético (MOREIRA et al., 2013). Entretanto, por serem alimentos frequentemente consumidos in natura, deve-se atentar para todas as etapas do processo produtivo, garantindo uma qualidade higiênico-sanitária satisfatória, evitando, assim, a contaminação por micro-organismos patogênicos. No entanto, são reconhecidas, as dificuldades encontradas na higienização e sanitização corretas destes alimentos, uma vez que as quantidades elevadas de hortaliças são higienizadas manualmente, demando demandam assim, uma maior mão de obra e controle do processo.

A ingestão de alimentos contaminados pode causar prejuízos à saúde de quem os consome (RODRIGUES et al., 2014), sendo de extrema importância a investigação da qualidade microbiológica das refeições e da água oferecidas nesses estabelecimentos, para que medidas efetivas de prevenção e controle de patógenos possam ser implementadas. O objetivo do presente estudo foi avaliar a qualidade microbiológica das saladas, seus ingredientes e da água servidas em um Restaurante Universitário do Triângulo Mineiro, Minas Gerais, Brasil.

\section{MATERIAL E MÉTODOS}

\section{Coleta e preparo das amostras de saladas}

Foram avaliadas 10 amostras de ingredientes (tomate, acelga, trigo para quibe, pepino, repolho e abacaxi) e 10 amostras de saladas prontas (Almeirão, alface e uva passa; Acelga e cenoura; Tabule; Repolho e abacaxi e Acelga e tomate) servidas em um Restaurante Universitário do Triângulo Mineiro no período de março a julho de 2014, coletadas de acordo com as normas estabelecidas na RDC $n^{\circ} 12$ de janeiro de 2001 (BRASIL, 2001). Cada a mostra de alimento, correspondente a $200 \mathrm{~g}$, foi colhida e acondicionada em sacos esterilizados contendo as seguintes informações: data, hora da coleta e tipo de produto. A seguir, as amostras foram armazenadas sob refrigeração até a chegada ao laboratório de microbiologia onde foram analisadas imediatamente.

Assepticamente, foram pesados $25 \mathrm{~g}$ de cada amostra de alimento que, posteriormente, foram colocadas em um saco plástico esterilizado e adicionadas a $225 \mathrm{~mL}$ de água peptonada $0,1 \%$ para a diluição $1 / 10$. Em seguida as amostras foram homogeneizadas em stomacher por 60 segundos a $240 \mathrm{rpm}$ e foram preparadas diluições seriadas $1 / 100$ e $1 / 1000$ por adição de alíquotas de $1 \mathrm{~mL}$ da diluição anterior em $9 \mathrm{~mL}$ de água peptonada $0,1 \%$.

\section{Coleta e preparo das amostras de água de consumo}

Cinco amostras de $100 \mathrm{~mL}$ de água dos bebedouros do Restaurante foram coletadas assepticamente, acondicionadas em sacos esterilizados e encaminhadas sob refrigeração ao laboratório.

\section{Análises microbiológicas}

Para verificação de coliformes totais e termotolerantes nas amostras de alimentos e água foi utilizada a técnica do número mais provável (NMP) (APHA, 2001). Três alíquotas de $1 \mathrm{~mL}$ de cada uma das diluições das amostras de alimentos e alíquotas de 10,1 e 0,1 mL das amostras de água foram inoculadas em uma série de três tubos contendo caldo Lauril Sulfato Triptose (LST) com incubação a $35^{\circ} \mathrm{C}$ por 
24-48h, em que a presença de gás e turvação foi o indicativo da presença de coliformes. Os tubos que apresentaram formação de gás e turvação foram submetidos ao teste para a confirmação de coliformes totais e termotolerantes. Para isso, uma alçada de cada tubo suspeito foi transferida para tubos contendo caldo Verde Brilhante (VB) e caldo $E$. coli (EC). Os tubos com caldo VB foram incubados em estufa a $35^{\circ} \mathrm{C}$ por $24-48 \mathrm{~h}$, em que a produção de $\mathrm{g}$ ás e turvação foi confirmativa da presença de coliformes totais. Os tubos com caldo EC foram incubados em banho maria por $24 \mathrm{~h}$ a $44,5^{\circ} \mathrm{C}$, nos quais a presença de gás e turvação após esse período confirmou a presença de coliformes termotolerantes.

Os resultados obtidos foram comparados com a tabela do NMP (APHA, 2001) e analisados por meio de estatística descritiva.

\section{RESULTADOS E DISCUSSÃO \\ Qualidade microbiológica das saladas e ingredientes}

Os valores para coliformes termotolerantes das amostras de saladas prontas analisadas variaram de $<3$ a $>1100 \mathrm{NMP} / \mathrm{g}$ (Tabela 1), sendo que 40\% apresentaram valores acima dos recomendados pela legislação RDC $n^{\circ} 12$ de 2001, que é de até 100NMP/g (BRASIL, 2001). A salada que apresentou maiores valores de contaminação foi a de almeirão, alface e uva passa (>1100 NMP/g), indicando qualidade higiênico-sanitária inadequada e possível contaminação de origem fecal. Os valores encontrados neste estudo para coliformes termotolerantes são menores que os encontrados por SOARES \& SANTOS (2014), em que todas as amostras analisadas apresentaram valores em desacordo com a legislação variando de 1,0 $\mathrm{x}$ $10^{3}$ a $1,5 \times 10^{3 .} \mathrm{NMP} / \mathrm{g}$.

As demais amostras (60\%) apresentaram valores dentro dos padrões aceitáveis recomendados pela RDC no 12 de 2001, estando apropriadas para 0 consumo. Entretanto, de acordo com CALIL et al. (2014) deve-se levar em consideração que a presença de coliformes termotolerantes independentemente da quantidade, pode indicar contaminação de origem fecal, indicando condições sanitárias e de higiene insatisfatórias.

TABELA 1 Contaminação por coliformes totais e termotolerantes em amostras de saladas de um restaurante universitário do Triângulo Mineiro, Minas Gerais, Brasil.

\begin{tabular}{lcccc}
\hline \multicolumn{1}{c}{ Amostra } & $\begin{array}{c}\text { Número de } \\
\text { amostras } \\
\text { analisadas }\end{array}$ & $\begin{array}{c}\text { Coliformes } \\
\text { totais } \\
\text { (NMP/g) }\end{array}$ & $\begin{array}{c}\text { Coliformes } \\
\text { termotolerantes } \\
\text { (NMP/g) }\end{array}$ & $\begin{array}{c}\text { \% amostras } \\
\text { acima do } \\
\text { padrão* }\end{array}$ \\
\hline Almeirão, alface e uva passa & 1 & $>1000$ & $>1100$ & $100 \%$ \\
\hline Acelga e cenoura & 1 & 1100 & 240 & $100 \%$ \\
\hline Tabule & 4 & 93 a $>1100$ & $<3$ a 23 & $0 \%$ \\
\hline $\begin{array}{l}\text { Repolho e abacaxi } \\
\text { Acelga e tomate }\end{array}$ & 2 & 11 a 460 & $<3$ a 460 & $50 \%$ \\
\hline $\begin{array}{l}\text { *Padrão estabelecido pela } \\
\text { termotolerantes: até 100 NMP/g. }\end{array}$ & 2 & 460 a $>1100$ & 43 a 460 & $50 \%$ \\
\hline
\end{tabular}

Um estudo realizado por BARROS et al. (2013), com o objetivo de verificar a qualidade microbiológica de frutas e hortaliças comercializadas em um município do Ceará, constatou que $100 \%$ das amostras de alface estavam em desacordo com a legislação quando avaliadas a quantidade de coliformes termotolerantes. FARIAS et al., (2011), com objetivo de analisar os principais alimentos que compõem as 
refeições servidas em uma unidade de alimentação hospitalar, constataram que todas as saladas analisadas apresentaram valores para coliformes termotolerantes $<0,3 \mathrm{NMP} / \mathrm{g}$, estando em acordo com o preconizado pela legislação.

O grupo coliforme é composto por bactérias de origem fecal e ambiental. A presença de coliformes termotolerantes é indicativo de contaminação fecal, pois estas possuem pequena capacidade de colonização no ambiente, ao contrário dos coliformes totais, cuja presença em alimentos e água pode indicar tanto contaminação de origem fecal, quanto ambiental (SOUSA, 2006).

As análises realizadas evidenciaram a presença de coliformes totais em todas as amostras (Tabela 1). Embora não haja limites estabelecidos de valores para coliformes totais, a maioria das saladas apresentou valores altos (iguais ou superiores a $1000 \mathrm{NMP} / \mathrm{g}$ ) evidenciando uma alta contaminação microbiana, indicando condições higiênico-sanitárias insatisfatórias nas várias etapas do processo de produção, por exemplo, ingredientes contaminados, manipulação inadequada e permanência do alimento em temperaturas inapropriadas por longos períodos. Além disso, esta alta contaminação pode indicar sanitização e processamento inadequados (SOUSA, 2006). De acordo com CALIL et al., (2014), as saladas cruas são altamente susceptíveis à contaminação microbiana, podendo esta ocorrer em qualquer etapa do processo produtivo.

Valores semelhantes aos encontrados neste estudo foram também obtidos por SOARES \& SANTOS (2014) onde todas as amostras de saladas analisadas apresentaram contaminação por este grupo de micro-organismos. Por outro lado, BAGATIN et al., (2013), analisando as condições higiênico-sanitárias da alimentação da rede municipal de ensino de Terra-Boa-PR, detectaram que apenas uma das amostras de hortaliças analisadas apresentou valor superior a $1100 \mathrm{NMP} / \mathrm{g}$ para coliformes totais.

Como os resultados haviam demonstrado altos níveis de contaminação nas amostras, foram realizadas análises com o objetivo de determinar a origem da contaminação. Para este fim, foram analisadas amostras dos ingredientes de cada salada separadamente, uma vez que alguns eram manipulados no local onde ocorria a produção e outra parte já chegavam ao local minimamente processados. Os resultados estão descritos na Tabela 2.

TABELA 2 Contaminação por coliformes totais e termotolerantes em amostras de ingredientes e saladas de um restaurante universitário do Triângulo Mineiro, Minas Gerais, Brasil.

\begin{tabular}{|c|c|c|c|c|c|}
\hline Amostra & $\begin{array}{l}\text { Número de } \\
\text { amostras } \\
\text { analisadas }\end{array}$ & Ingredientes & $\begin{array}{l}\text { Coliformes } \\
\text { totais NMP/g }\end{array}$ & $\begin{array}{c}\text { Coliformes } \\
\text { termotolerantes } \\
\text { NMP/g }\end{array}$ & $\begin{array}{l}\text { \% amostras } \\
\text { acima do } \\
\text { padrão * }\end{array}$ \\
\hline \multirow{4}{*}{ Tabule } & \multirow{4}{*}{2} & Trigo & 93 a 460 & 7,4 a 290 & $50 \%$ \\
\hline & & Tomate & 240 a 1100 & 0 a 15 & $0 \%$ \\
\hline & & Pepino & 23 a 240 & $<3$ a 15 & $0 \%$ \\
\hline & & Salada pronta & $93 a>1100$ & $<3$ & $0 \%$ \\
\hline \multirow{3}{*}{$\begin{array}{l}\text { Acelga e } \\
\text { Tomate }\end{array}$} & \multirow[t]{3}{*}{1} & Tomate & 240 & 240 & $100 \%$ \\
\hline & & Acelga & 460 & 150 & $100 \%$ \\
\hline & & Salada pronta & 460 & 460 & $100 \%$ \\
\hline \multirow{3}{*}{$\begin{array}{l}\text { Repolho e } \\
\text { abacaxi }\end{array}$} & \multirow[t]{3}{*}{1} & Repolho & 23 & 3,6 & $0 \%$ \\
\hline & & Abacaxi & 7,2 & $<3$ & $0 \%$ \\
\hline & & Salada pronta & 11 & $<3$ & $0 \%$ \\
\hline
\end{tabular}

*Padrão estabelecido pela RDC 12 de janeiro de 2001 (BRASIL, 2001) para coliformes termotolerantes:até $100 \mathrm{NMP} / \mathrm{g}$.

ENCICLOPÉDIA BIOSFERA, Centro Científico Conhecer - Goiânia, v.11 n.22; p. 3180 
De acordo com os resultados encontrados é possível observar que no tabule o ingrediente com maior porcentagem de contaminação foi o trigo, entretanto, ao se analisar a salada de tabule pronta é possível verificar que os valores encontram-se dentro dos aceitáveis pela legislação. Uma das prováveis causas desta diminuição da contaminação é a redução da concentração do ingrediente de maior contaminação, o trigo, no produto final.

Buscando investigar melhor outras causas para este resultado, foi analisada a salada de tabule antes do processo de tempero e após o processo. Os resultados encontrados demonstram que o número de coliformes termotolerantes na salada sem tempero foi de $7,4 \mathrm{NMP} / \mathrm{g}$ enquanto na salada temperada foi de $<3 \mathrm{NMP} / \mathrm{g}$. Já para coliformes totais foi encontrado um valor de $93 \mathrm{NMP} / \mathrm{g}$ na salada com tempero, contra $1100 \mathrm{NMP} / \mathrm{g}$ encontrado na salada antes do tempero ser colocado, demoNstrando uma redução significativa na carga microbiana após esta etapa.

A diminuição da contaminação por coliformes pode ter relação com a utilização de temperos com ação bacteriostática e bactericida como o sal e limão. Um estudo realizado por SANTOS et al. (2010) constatou que o uso do suco de limão pode ser considerado uma técnica eficaz para descontaminação de vegetais folhosos. Em um estudo realizado por SEGUN \& KARAPINAR (2004), foi observada uma redução a valores indetectáveis de Salmonella Typhimurium viáveis em cenouras tratadas com suco de limão. Os mesmos autores em outro estudo (SEGUN \& KARAPINAR, 2005) verificaram que o tratamento com suco de limão em folhas de rúcula e amostras de cebolinha inoculadas com Salmonella Typhimurium levou a uma redução significativa das contagens, com valores variando entre 1,23 e 4,17 log UFC/g e 0,87-2,93, respectivamente.

De acordo com ANBALAGAN et al. (2014) o cloreto de sódio ( $\mathrm{NaCl}$ ) aumenta a pressão osmótica e diminui a atividade de água no ambiente, inibindo assim o crescimento microbiano. Um estudo realizado por BUCHANAN \& KLAWITTER (1992) constatou que à medida que as concentrações de $\mathrm{NaCl}$ aumentaram no meio, a taxa crescimento de Escherichia coli 0157:H7 diminuíam, sendo esse efeito mais acentuado quando outras variáveis como temperatura e pH não estavam em faixas ótimas.

Ao analisar os ingredientes da salada de acelga com tomate, foi possível observar que todos encontravam-se com valores acima do recomendado pela legislação vigente, podendo-se concluir que a fonte provável da contaminação foram os ingredientes. Já na salada de repolho com abacaxi, apesar dos valores de coliformes termotolerantes apresentarem-se dentro dos preconizados pela legislação, os valores de coliformes totais indicam prováveis erros no processo produtivo. Sabe-se que o alimento pode ser contaminado por diversas formas, dentre elas destacam-se a sanitização inadequada ou ineficiente na etapa de prépreparo, contaminação cruzada com superfícies ou equipamentos contaminados e principalmente através do manipulador de alimentos (ANDRADE et al., 2003; KOCHANSKI et al., 2009; ABREU et al., 2011).

\section{Qualidade microbiológica da água de consumo}

Foram analisadas cinco amostras de água e todas apresentaram valores de acordo com a portaria $n^{\circ} 2914$ do Ministério da Saúde (BRASIL, 2011), que estabelece ausência de coliformes totais e termotolerantes em $100 \mathrm{~mL}$ da amostra, estando adequadas para o consumo humano. Resultado semelhante foi observado no estudo de FORTUNA et al., (2007), que avaliaram a qualidade microbiológica das 
águas dos bebedouros da Universidade Federal de Juiz de Fora onde 97,22\% das amostras analisadas encontravam-se de acordo com as normas estabelecidas. SANTOS et al., (2014), ao realizarem análise microbiológica da água de bebedouros em uma escola pública no Distrito Federal, também obtiveram ausência de coliformes totais e termotolerantes em todas amostras analisadas.

\section{CONCLUSÃO}

Apesar dos resultados satisfatórios para as amostras de água, os resultados constatados para saladas e seus ingredientes indicam prováveis falhas na higienização das hortaliças e superfícies que entram em contato com o alimento e/ou contaminação por meio dos manipuladores, que necessitam ser corrigidas por meio de maior controle de fornecedores e das etapas de preparação e por treinamentos para os manipuladores.

\section{REFERÊNCIAS}

ABREU, E.S.; MEDEIROS, F.S.; SANTOS, D. A. Análise microbiológica de mãos de manipuladores de alimentos do município de Santo André. Revista Univap, v. 17, n. 30, p. 39-57, 2011.

AKUTSU, R.C.; BOTELHO, R.A.; CAMARGO, E.B.; SÁVIO, K.E.O.; ARAÚJO, W.C. Adequação das boas práticas de fabricação em serviços de alimentação. Revista de Nutrição, v.18, n.3, p. 419-427, 2005.

AMSON, G.V.; HARACEMIV S.M.C.; MASSON, M.L. Levantamento de dados epidemiológicos relativos à ocorrências/surtos de doenças transmitidas por alimentos (DTAs) no estado do Paraná-Brasil, no período de 1978 a 2000 . Ciência e agrotecnologia, Lavras, v. 30, n. 6, p. 1139-1145, 2006.

ANBALAGAN, M.; PRABU, P.G.; KRISHNAVENI, R.E.; MANIVANNAN, S. Effect of Sodium Chloride $(\mathrm{NaCl})$ on the Bacterial Load in Chicken, Mutton and Beef Meat Samples in Relation to Meat Spoilage. International Journal of Research in Zoology, v.4, n.1, p.1-5, 2014.

ANDRADE, N.J.; SILVA, R.M.M.; BRABES, K.C.S. Avaliação das condições microbiológicas em unidades de alimentação e nutrição. Ciência e agrotecnologia, Lavras, V.27, n.3, p.590-596, 2003.

APHA. American Public Health Association. DOWNES, F. P.; ITO, K. Compendium of Methods for the Microbiological Examination of Foods. 4th ed. American Public Health Association-APHA, 2001, 676p.

BAGATIN, A.M.; RIBEIRO, A.B.; TONET, A. Hygienic-sanitary conditions of school meals from Municipal Schools in Terra Boa, PR (Brazil). Revista Brasileira de Pesquisa em Alimentos, v. 2, n. 2, 2013.

BARROS, L.E.B.; SANTOS, J.E.F.; MOREIRA, I.S.; SOUSA, F.C.; NUNES, J.S. Qualidade microbiológica de frutas e hortaliças comercializadas na cidade de 
Juazeiro do Norte-CE. Revista Verde de Agroecologia e Desenvolvimento Sustentável, v. 8, n. 3, p. 23-26, 2013.

BEZERRA, I.N.; SOUZA, A.M.; PEREIRA, R.A.; SICHIERI, R. Consumption of foods away from home in Brazil. Revista de Saúde Pública, v. 47, p. 200s-211s, 2013.

BRASIL. Lei 11.346 de 15 de setembro de 2006. Lei Orgânica de Segurança Alimentar e Nutricional. Diário Oficial da União, 2006. Disponível em: <http://www.planalto.gov.br/ccivil_03/_ato2004-2006/2006/lei/l11346.htm>. Acesso em: 08/08/2015.

Agência Nacional de Vigilância Sanitária. Resolução no 12, de 02 de janeiro de 2001. Estabelece regulamento técnico sobre os padrões microbiológicos para alimentos. Diário Oficial da União, 2001. Disponível em: <http://portal.anvisa.gov.br/wps/wcm/connect/1a86cd804c21ea589d1adddc39d59d3 e/rdc0012_16_02_2012.pdf?MOD=AJPERES>. Acesso em: 08/08/2015.

. Ministério da Saúde. Portaria no 2914 de 12 de dezembro de 2011. Dispõe sobre os procedimentos de controle e de vigilância da qualidade da água para consumo humano e seu padrão de potabilidade. Diário Oficial da União, 2011.

.Vigilância Epidemiológica das Doenças Transmitidas por Alimentos VE-DTA. Ministério da Saúde, SINAN. 2014. Disponível em: http://www.anrbrasil.org.br/new/pdfs/2014/3_PAINEL_1_ApresentacaoRejaneAlvesVi gilanciaEpidemiologica-VE-DTA-Agosto_2014_PDF.pdf. Acesso em 08/08/15.

BUCHANAN, R. L.; KLAWITTER, L. A. The effect of incubation temperature, initial $\mathrm{pH}$, and sodium chloride on the growth kinetics of Escherichia coli O157: H7. Food Microbiology, v. 9, n. 3, p. 185-196, 1992.

CALIL, E.M.B.; FERREIRA, F.L.A.; BRAZÃO, C.S.; SOVENHI, C.C. Qualidade microbiológica de saladas oferecidas em restaurantes tipo self-service. Atas de Saúde Ambiental-ASA, v. 1, n. 1, p. 36-42, 2014.

CODEX ALIMENTARIUS COMMISSION (CDC). Recommended International Code of Practice- General Principles of food hygiene. CAC/RCP 1. 2003.

FARIAS, J.K.R.; PEREIRA, M.M.S.; FIGUEIREDO, E.L. Avaliação de Boas Práticas e contagem microbiológica das refeições de uma unidade de alimentação hospitalar do município de São Miguel do Guamá- Pará. Alimentos e Nutrição Araraquara, v. 22, n. 1, p. 113-119, 2011.

FORTUNA, J.L.; RODRIGUES, M.T.; SOUZA, S.L.; SOUZA, L. Análise microbiológica da água dos bebedouros do campus da Universidade Federal de Juiz de Fora (UFJF): coliformes totais e termotolerantes. Higiene alimentar, v. 21, n. 153, p. 102-105, 2007.

JERBA V.F.; PILEGGI, M. Água: transporte passivo de microorganismos? Ciências biológicas e da saúde, v.1, n.6, p.21-27, 2000. 
KOCHANSKI, S.; PIEROZAN, M.K.; MOSSI, A.J.; TREICHEL, H.; CANSIAN, R.L.; GHISLENI, C.P.; TONIAZZO, G. Avaliação das condições microbiológicas de uma unidade de alimentação e nutrição. Alimentos e Nutrição Araraquara, v. 20, n. 4, p. 663-668, 2009.

MENDES, R. A.; AZEREDO, R.M.C.; COELHO, A.I.M.; OLIVEIRA, S.S.; COELHO, M.S.L. Contaminação ambiental por Bacillus cereus em unidade de alimentação e nutrição. Revista de Nutrição, v. 17, n. 2, p. 255-261, 2004.

MENDES, R.A.; COELHO, A.I.M.; AZEREDO, R.M.C. Contaminação por Bacillus cereus em superfícies de equipamentos e utensílios em unidade de alimentação e nutrição. Ciência \& Saúde Coletiva, v. 16, n.9, p.3933-3938, 2011.

MOREIRA, I.D.S.; SOUZA, F.C.; SANTOS, F.M.; FEITOSA, M.K.S.B.; MARQUES, L.F. Eficiência de soluções antimicrobiana na desinfecção de alface tipo crespa comercializada em feira livre. Revista Verde de Agroecologia e Desenvolvimento Sustentável, v. 8, n. 2, p. 171-177, 2013.

NUNES, M. M. Qualidade microbiológica de alimentos prontos para o consumo no distrito federal e avaliação de risco quantitativo da exposição da população brasileira a Staphylococcus aureus pelo consumo de queijo minas frescal. 2013. 130 f. Tese (Doutorado em Ciências da Saúde) - Universidade de Brasília, Brasília-DF, 2013.

RODRIGUES, B. F.; GÓES, J.A.W.; CARDOSO, R.C.V.; SOUZA, W.M.; FERREIRA, T.C.B. O comércio de comida de rua no centro histórico de Salvador-BA: caracterização da oferta de alimentos e aspectos higiênico-sanitários. Segurança Alimentar e Nutricional, Campinas, v. 21, n.1, p. 347-358, 2014.

SANTOS, J.A.; SILVA, J.X.; REZENDE, A.J. Avaliação Microbiológica de Coliformes Totais e Termotolerantes em Água e Bebedouros de Uma Escola Pública no Gama Distrito Federal. Revista de Divulgação Científica Sena Aires, v. 3, n. 1, p. 9-15, 2014.

SANTOS, Y.O.; ALMEIDA, R.C.C.; GUIMARÃES, A.G.; ALMEIDA, P.F. Hygienicsanitary quality of vegetables and evaluation of treatments for the elimination of indigenous E. coli and E. coli O157:H7 from the surface of leaves of lettuce (Lactuca sativa L.). Food Science and Technology (Campinas), v. 30, n. 4, p. 1083-1089, 2010.

SANTOS, R. M. S.; GOUVEIA, D.S.; ROCHA, A.P.T.; SILVA, W.M.; LINS, A.D.F. Avaliação de restaurante universitário por meio do regulamento técnico de boas práticas para serviços de alimentação. Revista Verde de Agroecologia e Desenvolvimento Sustentável, v. 2. n.1, p.26-32, 2015.

SEGUN, I. Y.; KARAPINAR, M. Effectiveness of lemon juice, vinegar and their mixture in the elimination of Salmonella typhimurium on carrots (Daucus carota L.). International Journal of Food Microbiology, v. 96, n. 3, p. 301-305, 2004. 
Effectiveness of household natural sanitizers in the elimination of Salmonella typhimurium on rocket (Eruca sativa Miller) and spring onion (Allium cepa L.). International Journal of Food Microbiology, v. 98, n. 3, p. 319-323, 2005.

SOARES, R.P.; DOS SANTOS M.L.B. Análise microbiológica de saladas cruas em restaurantes de Teresina-PI. Revista Interdisciplinar, v. 7, n. 2, p. 11-17, 2014.

SOUSA, C.P. Segurança alimentar e doenças veiculadas por alimentos: utilização do grupo coliforme como um dos indicadores de qualidade de alimentos. Revista de Atenção Primária à Saúde, v. 9, n. 1, p. 83-8, 2006. 